\title{
Contribution of epigenetics in diabetic retinopathy
}

\author{
KOWLURU Renu A.* \& MISHRA Manish \\ Kresge Eye Institute, Wayne State University, Detroit, MI, 48201, USA
}

Received December 4, 2014; accepted February 4, 2015; published online May 27, 2015

\begin{abstract}
Diabetes has become the epidemic of the 21 st century, and with over $90 \%$ patients with diabetes becoming at a risk of developing retinopathy, diabetic retinopathy has emerged as a major public health concern. In spite of cutting edge research in the field, how retina and its vasculature are damaged by the diabetic milieu remains ambiguous. The environmental factors, life style or disease process can also bring in modifications in the DNA, and these epigenetic modifications either silence or activate a gene without altering the DNA sequence. Diabetic environment up- or downregulates a number of genes in the retina, and emerging research has shown that it also facilitates epigenetic modifications. In the pathogenesis of diabetic retinopathy, the genes associated with important enzymes (e.g., mitochondrial superoxide dismutase, matrix metalloproteinase- 9 and thioredoxin interacting protein) and transcriptional factors are epigenetically modified, the enzymes responsible for these epigenetic modifications are either activated or inhibited, and the levels of microRNAs are altered. With epigenetic modifications taking an important place in diabetic retinopathy, it is now becoming critical to evaluate these modifications, and understand their impact on this slow progressing blinding disease.
\end{abstract}

diabetic retinopathy, epigenetic modifications, histone acetylation, histone methylation, miRNA

Citation: Kowluru RA, Mishra M. Contribution of epigenetics in diabetic retinopathy. Sci China Life Sci, 2015, 58: 556-563, doi: $10.1007 / \mathrm{s} 11427-015-4853-0$

Diabetic retinopathy is the most feared complication as over $90 \%$ of the patients with diabetes for more than 20 years encounter some symptoms of retinopathy. With the number of diabetes increasing at an alarming rate, the number of people with retinopathy is expected to increase from 126.6 million in 2011 to 191 million by 2030, and the vision-threatening retinopathy during this period will increase from 37.3 million to 56.3 million [1]. Due to high circulating glucose, the tiny blood vessels that nourish the retina are damaged, and in the early stages of the disease, microaneurysms, hemorrhages, intra-retinal microvascular abnormalities result in bleeding. If not controlled, this non-proliferative stage could progress to proliferative stage where the new vessels begin to grow, ultimately resulting in retinal

*Corresponding author (email: rkowluru@med.wayne.edu) detachment and blindness [2].

The pathogenesis of diabetic retinopathy is complex; although hyperglycemia is considered as the leading cause of the development of diabetic retinopathy, however, hypertension and dyslipidemia are also some of the major risk factors associated with the disease [3-5]. A number of metabolic abnormalities initiated by hyperglycemia are implicated in the development of diabetic retinopathy. Oxidative stress is regarded as one of the leading mechanisms in its development, and increase in oxidative stress in diabetic milieu is associated with a number of other interlinking metabolic abnormalities including the accumulation of advanced glycation end products, activation of protein kinase $\mathrm{C}$, polyol and hexosamine pathways [2,6-8]. Though many leading laboratories are involved in cutting edge research to understand the etiology of this complex disease, the exact mechanism responsible for its development remains elusive. 


\section{Genetics and diabetic retinopathy}

In addition to metabolic and physiologic factors, pathogenesis of a disease is also influenced by genetic factors. Due to variability in the severity of retinopathy among patients with diabetes with similar risk factors, however, genetic associations with diabetic retinopathy remain unclear. Genome-wide association studies have identified a number of genetic variants that could explain some of the inter-individual variations in the susceptibility of diabetes. A meta-analysis study has shown a significant variation in the AKRIBIgene, a gene encoding aldo-keto reductase family 1 member B1, and this rate limiting enzyme of the polyol pathway is strongly associated with diabetic retinopathy [9]. Another meta-analysis study with patients with type 2 diabetes has shown a protective role of Pro12Ala polymorphism in the peroxisome proliferator-activated receptor- $\gamma 2$ gene in the incidence of retinopathy [10]. In contrast, recent studies have failed to find any associations between vascular endothelial growth factor (VEGF)-related single nucleotide polymorphisms (rs6921438 and rs10738760) and the risk of retinopathy and nephropathy in patients with diabetes [11]. Thus, the association between genetic factors and diabetic retinopathy needs further investigation.

\section{Epigenetics and gene regulation}

Epigenetics is now emerging as one of the important factors in many diseases as it can regulate the complex interplay between genes and the environment, and these heritable changes can occur without any change in the DNA sequence. Epigenetic change is a regular and natural phenomenon, and can also be influenced by several factors including age, the environment, lifestyle and disease state $[12,13]$. Epigenetic modifications can act like switches helping to control gene activity and allowing alternations in genome function without altering the gene sequences. At least three major epigenetic modifications including DNA methylation, histone modification and non-coding RNA are considered to initiate and sustain changes in gene regulation [14,15].

DNA is not a static, fixed entity, but instead it is 'highly dynamic', and it responds to the environmental stimuli by modifying its properties in adapting to the changes [16]. Methylation of cytosine to 5-methyl cytosine $(5 \mathrm{mC})$ is considered as one of the major epigenetic modification; methylation of the $\mathrm{CpG}$ islands, a CG rich region in the promoter of many genes, changes protein-DNA interactions leading to alterations in chromatin structure, and this interferes with the binding of transcriptional machinery, resulting in gene suppression $[17,18]$. The hypomethylated DNA re-activates the repetitive genomic sequences, resulting in chromosomal instability and abnormal gene expres- sion $[19,20]$. DNA methylation is catalyzed by DNA methyl transferases (Dnmts), a family with five members-Dnmt1, Dnmt2, Dnmt3a, Dnmt3b and Dnmt3L; out of which only Dnmt1, Dnmt3a and Dnmt3b are catalytically active. Dnmt3a and Dnmt3b are de novo methyltransferases, and Dnmt1 is a maintenance enzyme important in regulating tissue-specific patterns of methylated cytosine residues $[21,22]$. Pathological Dnmt activity and aberrant $5 \mathrm{mC}$ formation have been linked with neurodegeneration [23]. $5 \mathrm{mC}$ can be oxidized to 5-hydroxymethylcytosine $(5 \mathrm{hmC})$ by ten-eleven translocation enzymes, and $5 \mathrm{hmC}$ can also be further oxidized to generate 5-formylcytosine and 5-carboxylcytosine [24]. A subfamily of DNA glycosylases are considered to promote active DNA demethylation by removing the 5-methylcytosine base, followed by cleavage of the DNA backbone at the abasic site, and the methylated cytosine is replaced by an unmethylated cytosine [25]. In contrast, the passive process involves absence/inactivation of Dnmt1 resulting hypomethylated DNA [26].

Chromatin, a composite structure of histones and nucleic acid, instructs the expression pattern of different genes, and conformational changes in the DNA, by altering the binding of transcription factors and its machinery, can change the gene expression. Among the 4-histone proteins, histone $2(\mathrm{H} 2)$ exists in 2-subtypes, H2A and H2B which along with $\mathrm{H} 3$ and $\mathrm{H} 4$ forms a tetrameric structure, wrapped with $\sim 146$ bp of nucleic acid [27]. This sophisticated DNA packaging still allows $\mathrm{N}$-terminal sequences of histones to undergo modifications including acetylation, methylation and phosphorylation. These modifications can either open or restrict access to DNA by directly altering the electrostatic potential and/or the structure of the local chromatin environment or indirectly alter the recruitment of the effector proteins [28]. Histone modifications are regulated by a balance between the enzymes inserting or removing a group $[29,30]$. Acetylation of histones is one of the most common modifications; acetylation opens up the chromatin structure, which allows recruitment and binding of the transcription factor and RNA polymerase II [31]. A group of enzymes with opposing functions maintain the required acetylation status, while histone acetyltransferases (HATs) inserts an acetyl group on a lysine of the histone; histone deacetylases (HDACs) remove the acetyl group [29]. In contrast to acetylation, methylation of histone, depending on the target site, can turns "off" or "on" the genes [32]. While trimethylation of histone $\mathrm{H} 3$ at lysine 4 (H3K4me3) is generally considered as an active mark for transcription, dimethylation of histone $\mathrm{H} 3$ at lysine $9(\mathrm{H} 3 \mathrm{~K} 9 \mathrm{me} 2)$ as a transcriptional silencing mark. In addition, depending on the degree of residue methylation, different functions can be expected; monomethylated H4K20 (H4K20me1) and H4K20me3 are considered as transcriptional repressors, $\mathrm{H} 4 \mathrm{~K} 20 \mathrm{me} 2$ is largely considered as an activator [32-35]. Histone methyltransferases (HMT) catalyze the transfer of one, two, or three methyl groups to lysine (and arginine) residues of his- 
tone proteins. There are two major types of HMTs, lysine-specific, which can be SET (Su(var)3-9, Enhancer of Zeste, Trithorax) domain containing or non-SET domain containing. Contrary to a relatively well defined histone methylating system, histone demethylation machinery is not well studied; LSD1, a lysine-specific histone demethylase, specifically removes methyl group from $\mathrm{H} 3 \mathrm{~K} 4 \mathrm{me}$ and H3K9me [36,37].

Recent studies have shown that DNA methylation and histone modifications could function in concordance [38]; for example, Dnmt1, methyl CpG binding protein 2 (MeCP2) and methyl-CpG-binding domain proteins (MBDs) could associate with HDAC (39) or CpG methylation could cooperate with euchromatic histone methyltransferase SETDB1/ESET in histone H3 lysine 9 trimethylation, resulting in gene regulation. In addition, histone modifying enzymes, SUV39h1 and EZH2 lysine histone methyltransferases can interact with Dnmt and regulate their functions [40-42], and PRMT5-mediated methylation of arginine could silence gene expression via recruiting Dnmt3A [43]. Thus, both histone modification and DNA methylation could regulate the same gene. Although these epigenetic modifications do not have to be permanent, their response to the changing environment, and passing to the successive generations, makes them one of the most important drug targets for a chronic disease like diabetic retinopathy.

Small noncoding RNAs ( 22 nucleotides) are also considered to regulate gene expression as these microRNAs (miRNA) bind to the complementary sequences in the $3^{\prime}$ untranslated region of mRNAs, and cleave mRNA resulting in decreased protein synthesis and expression of the targeted gene $[44,45]$. Methylation of DNA and histone, and miRNA appear to work in concordance as the function of Dnmts depends on histone modification patterns, such as $\mathrm{H} 3 \mathrm{~K} 9$ methylation and histone deacetylation and inhibition of Dnmts reactivates some of the miRNAs [46]. Since these epigenetic modifications are mainly caused by the local environment and can be passed on to the next generation, they are now being considered as some of the attractive targets for chronic disease, including diabetes and cancer [47].

\section{Epigenetic modification and diabetes}

Glucose is critically important for the organisms for survival, but sustained levels of high glucose are detrimental, and can initiate a number of metabolic, biochemical and genetic abnormalities. It affects regulation of genes throughout the body. Recent work has suggested that diabetic milieu favors epigenetic modifications in various organs associated with micro- and macro-vascular complications [8,48,49]. Genome-wide DNA methylation study using blood cells from patients with type 1 diabetes has identified 19 potential $\mathrm{CpG}$ sites that are prone to DNA methylation in diabetes. $S$-Adenosyl methionine (SAM), the donor of methyl group for DNA methylation, is shown to influence the expression of genes related with diabetic complications, and blood deficiency of SAM is reported in the patients with diabetic nephropathy [50-53], and leukocytes from diabetic patients have reduced Dnmts levels [54]. Global hypomethylation and reduced level of SAM are also observed in Zebrafish with chemically induced diabetes [55]. In contrast, in Zucker fatty rat, a model of type 2 diabetes, sustained global DNA hypermethylation is observed in the liver, and this is associated with abnormal metabolism of the methyl group [53]. These divergent patterns of DNA methylation in diabetes suggest that various tissues could be responding differently to diabetes.

Hyperglycemia is also associated with aberrant changes in $\mathrm{H} 3 \mathrm{~K} 4 \mathrm{me} 2$ and $\mathrm{H} 3 \mathrm{~K} 9 \mathrm{me} 2$ in human monocytic THP-1 cells and increases histone acetylation in the chromatin region containing the promoter of the transcription factor, nuclear factor kappa B (NF-kB)-p65 [56]. In vascular smooth muscle cells derived from type 2 diabetic mice, irreversibly decreased levels of both $\mathrm{H} 3 \mathrm{~K} 9 \mathrm{me} 3$ and methyltransferase Suv39H1 at the promoters of interleukin-6 and monocyte chemoattractant protein1 are observed, and SUV39H1 gene silencing irreversibly elevates the expression of inflammatory genes and decreases $\mathrm{H} 3 \mathrm{~K} 9 \mathrm{me} 3$ at their promoters [57]. Monocytes from case subjects enrolled in landmark the Diabetes Control and Complications Trial and the follow up Epidemiology of Diabetes Interventions and Complications study have shown a significant association between $\mathrm{H} 3 \mathrm{~K} 9$ acetylation and hemoglobin $\mathrm{A} 1 \mathrm{C}$ levels [58].

In addition to histone modifications and DNA methylation, miRNAs are also associated with various diabetic complications. Increased levels of miR-377 and miR-21 are observed in the human and mouse mesangial cells exposed to hyperglycemic milieu [59,60]. Increased miR-377 levels have been linked to the induction of fibronectin, which contributes to the renal fibrosis in hyperglycemia [59]. Glucose-induced miR-146a downregulation is mediated through the HAT p300, suggesting an interrelationship between histone acetylation and miR-146a mediated fibronectin expression and a possible functional link between miRNA expression and histone modification in diabetes [61]. Thus, epigenetic modifications appear to play an important role in the development of diabetes and its complications.

\section{Epigenetic modification in diabetic retinopa- thy}

Diabetic retinopathy, a slow progressing disease, is associated with a number of metabolic abnormalities [2,7,8], however, the role of epigenetic modifications in diabetic retinopathy is still not clear. In a Finnish study, an associa- 
tion between the polymorphism in $S U V 39 H 2$, a gene that encodes histone methyltransferases and microvascular complications, including retinopathy has been observed in patients with diabetes [62]. In a cross-sectional study with over 1,000 patients having type 2 diabetes, analysis of their family history has suggested a possible genetic and epigenetic basis for the development of diabetic retinopathy $[63,64]$. Experimental evidence using in vitro and in vivo models of diabetic retinopathy have shown that the activities of HDACs are increased and that of HATs are decreased in the retina and its capillary cells in diabetes, and global acetylation of histones is decreased [65]. However, contrary to this, others have shown significant increase in retinal histone acetylation in diabetes [66]; undermining the importance of further investigation into the role of histone modifying enzymes in the development of diabetic retinopathy.

Mitochondrial superoxide are considered as the unifying molecules connecting many metabolic abnormalities associated with diabetic retinopathy $[7,67,68]$, and in diabetes, retinal mitochondria are damaged and superoxide scavenging enzyme (superoxide dismutase) is dysfunctional [69]. We have shown that diabetes epigenetically modifies $\operatorname{Sod} 2$, the gene encoding mitochondrial superoxide dismutase, and H4K20me3, acetyl H3K9 and p65 subunit of NF- $\kappa B$ (p65) are increased at its promoter/enhancer, H3K4 is demethylated and LSD1 binding is increased. These results have clearly suggested that epigenetic modifications have a major role in the regulation of superoxide levels, and thus in the development of retinopathy [70,71]. Furthermore, epigenetic modifications are also implicated in the function of $\mathrm{Nrf} 2$, a master regulator which regulates the expression of stress responsive gene. Due to epigenetic modifications at the promoter of Kelch-like ECH associated protein 1 (Keapl, an intracellular inhibitor of Nrf2), the binding of transcriptional factor $\mathrm{Sp} 1$ is increased. This results in increased expression of Keap1 and Keap1 tries to restrain the redox sensitive transcription factor in the cytosol, impairing its transcriptional activity and increasing oxidative stress. Furthermore, due to increased $\mathrm{H} 3 \mathrm{~K} 4 \mathrm{me} 1$, Nrf2 binding at its glutamate-cysteine ligase-antioxidant response element region 4 Gclc-ARE4 is decreased, resulting in decreased transcripts of the catalytic subunit of glutamate-cysteine ligase, an important enzyme responsible for biosynthesis of the intracellular antioxidant, glutathione [72-74].

In the pathogenesis of diabetic retinopathy, activation of matrix metalloproteinase-9 (MMP-9) is shown to damage mitochondria, and this initiates the apoptotic machinery [75,76]. MMP-9 is regulated by NF- $\mathrm{KB}$ and the activation of $\mathrm{NF}-\kappa \mathrm{B}$ is modulated by the acetylation of its p65 subunit. Sirt1, a deacetylase, plays an important role in the acetylation-deacetylation of p65, and the activity of retinal Sirt1 is decreased and the acetylation of p65 is increased in diabetes [77]. Consistent with this, retina from human donors with diabetic retinopathy have decreased $\mathrm{H} 3 \mathrm{~K} 9 \mathrm{me} 2$ at $M M P-9$ promoter, acetyl H3K9 levels are elevated, and this facilitates the recruitment of p65 at its promoter and upregulates $M M P-9$, damaging mitochondria and increasing superoxide levels [78]. In addition, epigenetic modifications of thioredoxin interacting protein, an endogenous inhibitor of antioxidant thioredoxin, are associated with sustained Cox2 expression seen in the retina in diabetes $[79,80]$.

DNA methylation, an important epigenetic modification, is closely associated with the regulation of gene transcription $[17,18]$. A case control study using patients having type 2 diabetes has shown significantly higher levels of global DNA methylation in patients having diabetes with retinopathy compared to those with no retinopathy, and although global DNA methylation appears to be independent of retinopathy risk factors, e.g., hyperglycemia, dyslipidemia and hypertension, in these patients, the methylation status of DNA shows a correlation with the progression of retinopathy $[63,64]$. Experimental studies using in vitro and in vivo models of diabetic retinopathy have shown that the regulatory region of DNA polymerase gamma, an enzyme important in mitochondrial DNA biogenesis, is hypermethylated, and due to increased $\mathrm{CpG}$ methylation, its expression is reduced and its binding to the regulatory region of mtDNA is attenuated, resulting in subnormal mtDNA biogenesis [51]. These studies have clearly suggested that both the histone modifications and DNA methylation have important roles in maintaining mitochondrial homeostasis and regulating superoxide levels, which has an important role in the development of diabetic retinopathy.

In addition to modifications of histones and DNA, the small non-coding RNAs can also regulate post-transcriptional gene expression by binding to their target messenger RNAs, resulting in alterations in gene transcription $[44,45]$. These miRNAs are stable, and this makes them as ideal biomarkers in several diseases, including diabetes. Their function is somewhat complex as the same miRNA can target a number of genes, and the same gene can be targeted by a number of miRNA $[81,82]$. Studies with experimental models of diabetic retinopathy have revealed a number of miRNAs with either increase or decrease in their expressions. Experimental models of diabetic retinopathy have shown an association between the downregulation of miR-126, miR-146a and miR-200b and upregulation of VEGF, and downregulation of miR-146a is also associated with fibronectin production, and upregulation of miR-195 with downregulation of deacetylase Sirt1. Upregulation of miR-29b in the early stages of diabetes is considered to be protective against apoptosis of the retinal ganglion cells $[83,84]$. These studies have clearly suggested the important role for miRNAs in regulating various aspects of diabetic retinopathy, including blood retinal breakdown and neovascularization.

Thus, diabetic environment favors epigenetic modifica- 
tions in the retina; DNA methylation and miRNAs are altered and histones are modified. DNA methylation and histone modifications could also affect miRNA levels. Due to epigenetic modifications, the binding of transcription factors (e.g., NF- $\kappa \mathrm{B}$ and $\mathrm{Nrf} 2$ ) and the expression of genes (Sod2, MMP-9, Keap1, TXNIP, VEGF, etc.) become abnormal, resulting in the metabolic, physiological and structural abnormalities, and the development of diabetic retinopathy (Figure 1, Table 1).

\section{Therapeutic implications}

As mentioned above, epigenetic appears to play a major role in the development of diabetic retinopathy. Histone modifications have an important dynamic role in the regulation of gene expression; acetylation status of histones can directly influence the transcription of a gene. There is clearly a growing interest in the therapeutic use of HDAC inhibitors in the treatment of abnormalities in histone acetylases and deacetylases. Epigallocatechin-3-gallate is a strong histone acetylase inhibitor, and is shown to inhibit NF- $\kappa \mathrm{B}$ activation [85] and in the pathogenesis of diabetic retinopathy, activation of NF- $\kappa \mathrm{B}$ is considered to accelerate apoptosis of capillary cells, suggesting that inhibitor has potential to inhibit the development of diabetic retinopathy. Resveratrol, a naturally occurring compound found in grapes, wine and eucalyptus, is a potent activator of Sirt1, and it also inhibits some histone deacetylases [86]. In addition, curcumin [87] and genistein [88] are also shown to activate histone acetylases and inhibit deacetylases [89]. Vorinostat (suberanilohydroxamic acid), a HDAC inhibitor, is now approved by FDA for Cutaneous T-cell lymphoma [90]. As with histone acetylating-deacetylating enzymes, histone methyltransferases are also being considered as targets for therapeutics. Enhancer of Zeste Homolog 2 (EZH2), important for H3K27 methylation, has been shown to be inhibited by 3-deazaneplanocin, and specific inhibitors of EZH2, e.g., GSK126, seem to be showing promising results for the treatment of cancer. Epigenomic-based therapies targeting histone modifications are also being developed, and they offer new approaches for the treatment of ovarian cancer [91].

DNA methylation also plays a key role in gene regulation, and DNA methyltransferases are the key enzymes for DNA methylation. Nucleoside analogs incorporate into the DNA and trap all DNA methyltransferases, and the US Food and Drug Administration has already approved Dnmt inhibitors 5-azacytidine (5-Aza-CR; azacitidine; Vidaza) and 5-aza20-deoxycitidine (5-Aza-CdR; decitabine; Dacogen) for myeloid cancers and cutaneous $\mathrm{T}$ cell lymphoma. Non nucleotide analogue RG108 is now in pre-clinical trials, and MG98 in phase I/II clinical trials [92]. VEGF receptor promoter methylation is considered an important factor in determining the efficacy of the VEGF-targeted drugs on the proliferation of cancer tissue [93], and this has tremendous

Table 1 Epigenetic modifications in diabetic retinopathy

\begin{tabular}{cc}
\hline Enzymes/miRNAs & Targets/modifications \\
\hline KDM5A, LSD1 & Gclc promoter histone modification (H3K4me3, H3K4me1) \\
SetD7/9 & Keap1 promoter histone modification (H3K4me1) \\
LSD1 & MMP-9 promoter histone modification (H3K9me2, H3K9-Ac) \\
LSD1, SUV420h2 & TXNIP promoter \\
HAT (p300) & PolG1 promoter DNA methylation \\
Dnmts & Oxr 1, VEGF \\
$m i R-200 b$ & Rax \\
$m i R-129 b$ & $N F-\kappa B$ \\
$m i R-146$ &
\end{tabular}

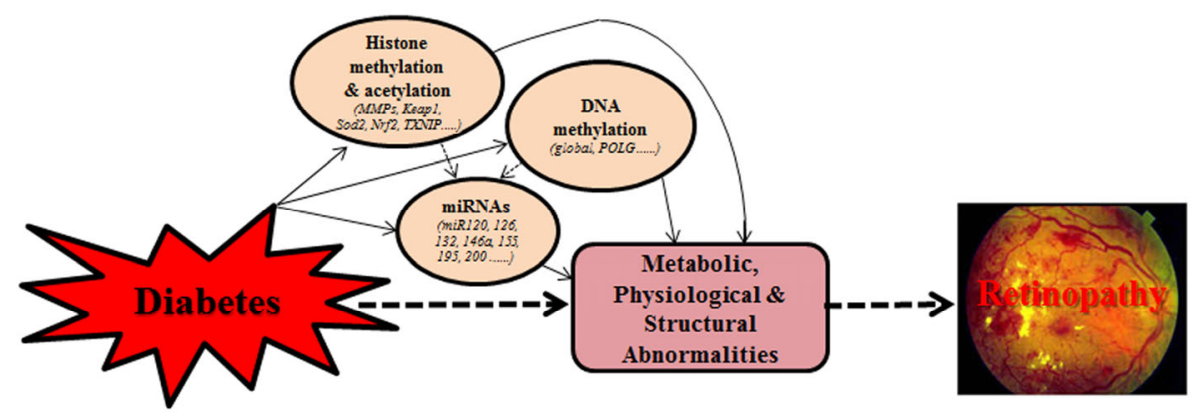

Figure 1 (color online) Sustained hyperglycemic insult results in a number of metabolic (e.g., PKC, AGEs, polyol pathway, oxidative stress), physiological (vascular permeability etc.) and structural (capillary cell loss, hemorrhages etc.) abnormalities in the retina that culminate in the development of retinopathy. In addition, diabetic environment also favors epigenetic modifications in the histones and DNA, and alters miRNA levels. These epigenetic modifications also fuel into the metabolic/physiological/structural abnormalities associated with the pathogenesis of diabetic retinopathy. 
clinical implications for diabetic retinopathy.

Since miRNAs are considered as potential diagnostic biomarkers for disease, double-stranded miRNA mimics and anti-mRNA antisense oligo-deoxyribonucleotide are being used to target specific miRNA [84]. Also, since one miRNA can have a number of targets, a therapy targeting a specific miRNA can also alter other pathways associated with the disease $[81,82]$. However, one of the major caveats with the miRNA-based therapy could be their access to the posterior part of the eye and trouble with crossing the blood-retina barrier.

As a number of epigenetic modifications are now being associated with the development of diabetic retinopathy, there is a great potential for therapeutics targeted towards these modifications to be applied for this sight-threatening disease.

1 Zheng Y, He M, Congdon N. The worldwide epidemic of diabetic retinopathy. Indian J Ophthalmol, 2012, 60: 428-431

2 Frank RN. Diabetic retinopathy. N Engl J Med, 2004, 350: 48-58

3 Lim LS, Wong TY. Lipids and diabetic retinopathy. Expert Opin Biol Ther, 2012, 12: 93-105

4 Zhang W, Liu H, Rojas M, Caldwell RW, Caldwell RB. Antiinflammatory therapy for diabetic retinopathy. Immunotherapy, 2011, 3: 609-628

5 Cheung N, Mitchell P, Wong TY. Diabetic retinopathy. Lancet, 2010, 376: $124-136$

6 Brownlee M. Biochemistry and molecular cell biology of diabetic complications. Nature, 2001, 414: 813-820

7 Kowluru RA, Chan PS. Oxidative stress and diabetic retinopathy. Exp Diabetes Res, 2007, 2007: 43603

8 Kowluru RA, Santos JM, Mishra M. Epigenetic modifications and diabetic retinopathy. Biomed Res Int, 2013, 2013: 635284

9 Abhary S, Hewitt AW, Burdon KP, Craig JE. A systematic meta-analysis of genetic association studies for diabetic retinopathy. Diabetes, 2009, 58: 2137-2147

10 Ma J, Li Y, Zhou F, Xu X, Guo G, Qu Y. Meta-analysis of association between the Pro12Ala polymorphism of the peroxisome proliferator-activated receptor- $\gamma 2$ gene and diabetic retinopathy in Caucasians and Asians. Mol Vis, 2012, 18: 2352-2360

11 Bonnefond A, Saulnier PJ, Stathopoulou MG, Grarup N, Ndiaye NC, Roussel R, Nezhad MA, Dechaume A, Lantieri O, Hercberg S, Lauritzen T, Balkau B, El-Sayed Moustafa JS, Hansen T, Pedersen O, Froguel P, Charpentier G, Marre M, Hadjadj S, Visvikis-Siest S. What is the contribution of two genetic variants regulating VEGF levels to type 2 diabetes risk and to microvascular complications? PLoS One, 2013, 8: e55921

12 Regha K, Sloane MA, Huang R, Pauler FM, Warczok KE, Melikant B, Radolf M, Martens JH, Schotta G, Jenuwein T, Barlow DP. Active and repressive chromatin are interspersed without spreading in an imprinted gene cluster in the mammalian genome. Mol Cell, 2007, 27: 353-366

13 Gemenetzi M, Lotery AJ. The role of epigenetics in age-related macular degeneration. Eye (Lond), 2014, 28: 1407-1417

14 Uribe-Lewis S, Woodfine K, Stojic L, Murrell A. Molecular mechanisms of genomic imprinting and clinical implications for cancer. Expert Rev Mol Med, 2011, 13: e2

15 Toiyama Y, Okugawa Y, Goel A. DNA methylation and microRNA biomarkers for noninvasive detection of gastric and colorectal cancer. Biochem Biophys Res Commun, 2014, 455: 43-57

16 Gravina S, Vijg J. Epigenetic factors in aging and longevity. Pflugers Arch, 2010, 459: 247-258

17 Jones PA, Takai D. The role of DNA methylation in mammalian epigenetics. Science, 2001, 293: 1068-1070

18 Lim U, Song MA. Dietary and lifestyle factors of DNA methylation. Methods Mol Biol, 2012, 863: 359-376

19 Esteller M. Cancer epigenomics: DNA methylomes and histonemodification maps. Nat Rev Genet, 2007, 8: 286-298

20 Gaudet F, Hodgson JG, Eden A, Jackson-Grusby L, Dausman J, Gray $\mathrm{JW}$, Leonhardt $\mathrm{H}$, Jaenisch R. Induction of tumors in mice by genomic hypomethylation. Science, 2003, 300: 489-492

21 Guibert S, Forne T, Weber M. Dynamic regulation of DNA methylation during mammalian development. Epigenomics, 2009, 1: 81-98

22 Majumdar S, Buckles E, Estrada J, Koochekpour S. Aberrant DNA methylation and prostate cancer. Curr Genomics, 2011, 12: 486-505

23 Deaton AM, Bird A. CpG islands and the regulation of transcription. Genes Dev, 2011, 2510: 1010-1022

24 Zhang P, Huang B, Xu X, Sessa WC. Ten-eleven translocation (Tet) and thymine DNA glycosylase (TDG), components of the demethylation pathway, are direct targets of miRNA-29a. Biochem Biophys Res Commun, 2013, 437: 368-373

25 Kohli RM, Zhang Y. TET enzymes, TDG and the dynamics of DNA demethylation. Nature, 2013, 502: 472-479

26 Zhu JK. Active DNA demethylation mediated by DNA glycosylases. Annu Rev Genet, 2009, 43: 143-166

27 Luger K, Mäder AW, Richmond RK, Sargent DF, Richmond TJ. Crystal structure of the nucleosome core particle at 2.8 A resolution. Nature, 1997, 389: 251-260

28 Gurard-Levin Z, Almouzni G. Histone modifications and a choice of variant: a language that helps the genome express itself. F1000Prime Rep, 2014, 6: 76

29 Ropero S, Esteller M. The role of histone deacetylases (HDACs) in human cancer. Mol Oncol, 2007, 1: 19-25

30 Sarkar S, Goldgar S, Byler S, Rosenthal S, Heerboth S. Demethylation and re-expression of epigenetically silenced tumor suppressor genes: sensitization of cancer cells by combination therapy. Epigenomics, 2013, 5: 87-94

31 Glozak MA, Seto E. Histone deacetylases and cancer. Oncogene, 2007, 26: 5420-5432

32 Kouzarides T. Histone methylation in transcriptional control. Curr Opin Genet Dev, 2002, 12: 198-209

33 Kubicek S, Jenuwein T. A crack in histone lysine methylation. Cell, 2004, 119: 903-906

34 Kubicek S, O'Sullivan RJ, August EM, Hickey ER, Zhang Q, Teodoro ML, Rea S, Mechtler K, Kowalski JA, Homon CA, Kelly TA, Jenuwein T. Reversal of $\mathrm{H} 3 \mathrm{~K} 9 \mathrm{me} 2$ by a small-molecule inhibitor for the G9a histone methyltransferase. Mol Cell, 2007, 25: $473-481$

35 Nightingale KP, O'Neill LP, Turner BM. Histone modifications: signalling receptors and potential elements of a heritable epigenetic code. Curr Opin Genet Dev, 2006, 16: 125-136

36 Forneris F, Binda C, Battaglioli E, Mattevi A. LSD1: oxidative chemistry for multifaceted functions in chromatin regulation. Trends Biochem Sci, 2008, 33: 181-189

37 Musri MM, Carmona MC, Hanzu FA, Kaliman P, Gomis R, Párrizas M. Histone demethylase LSD1 regulates adipogenesis. J Biol Chem, 2010, 285: 30034-30041

38 Cedar H, Bergman Y. Linking DNA methylation and histone modification: patterns and paradigms. Nat Rev Genet, 2009, 10: 295-304

39 Fahrner JA, Eguchi S, Herman JG, Baylin SB. Dependence of histone modifications and gene expression on DNA hypermethylation in cancer. Cancer Res, 2002, 62: 7213-7218

40 Lehnertz B, Ueda Y, Derijck AA, Braunschweig U, Perez-Burgos L, Kubicek S, Chen T, Li E, Jenuwein T, Peters AH. Suv39h-mediated histone H3 lysine 9 methylation directs DNA methylation to major satellite repeats at pericentric heterochromatin. Curr Biol, 2003, 13: 1192-1200

41 Fuks F, Hurd PJ, Deplus R, Kouzarides T. The DNA methyltransferases associate with HP1 and the SUV39H1 histone methyltransferase. Nucleic Acids Res, 2003, 31: 2305-2312 
42 Vire E, Brenner C, Deplus R, Blanchon L, Fraga M, Didelot C, Morey L, Van Eynde A, Bernard D, Vanderwinden JM, Bollen M, Esteller M, Di Croce L, de Launoit Y, Fuks F. The polycomb group protein EZH2 directly controls DNA methylation. Nature, 2006, 439: 871-874

43 Zhao Q, Rank G, Tan YT, Li H, Moritz RL, Simpson RJ, Cerruti L, Curtis DJ, Patel DJ, Allis CD, Cunningham JM, Jane SM. PRMT5-mediated methylation of histone H4R3 recruits DNMT3A, coupling histone and DNA methylation in gene silencing. Nat Struct Mol Biol, 2009, 16: 304-311

44 Dykxhoorn DM, Novina CD, Sharp PA. Killing the messenger: short RNAs that silence gene expression. Nat Rev Mol Cell Biol, 2003, 4: $457-467$

45 Garzon R, Calin GA, Croce CM. MicroRNAs in Cancer. Annu Rev Med, 2009, 60: 167-179

46 Baer C, Claus R, Plass C. Genome-wide epigenetic regulation of miRNAs in cancer. Cancer Res, 2013, 73: 473-477

47 Cabezas-Cruz A, Lancelot J, Caby S, Oliveira G, Pierce RJ. Epigenetic control of gene function in schistosomes: a source of therapeutic targets? Front Genet, 2014, 5: 317

48 Stankov K, Benc D, Draskovic D. Genetic and epigenetic factors in etiology of diabetes mellitus type 1. Pediatrics, 2013, 132: 1112-1122

49 Kato M, Natarajan R. Diabetic nephropathy-emerging epigenetic mechanisms. Nat Rev Nephrol, 2014, 10: 517-530

50 Poirier LA, Brown AT, Fink LM, Wise CK, Randolph CJ, Delongchamp RR, Fonseca VA. Blood S-adenosylmethionine concentrations and lymphocyte methylenetetrahydrofolate reductase activity in diabetes mellitus and diabetic nephropathy. Metabolism, 2001, 50: 1014-1018

51 Tewari S, Zhong Q, Santos JM, Kowluru RA. Mitochondria DNA replication and DNA methylation in the metabolic memory associated with continued progression of diabetic retinopathy. Inves Ophthalmol Vis Sci, 2012, 53: 4881-4888

52 Williams KT, Garrow TA, Schalinske KL. Type I diabetes leads to tissue-specific DNA hypomethylation in male rats. J Nutr, 2008, 138: 2064-2069

53 Williams KT, Schalinske KL. Tissue-specific alterations of methyl group metabolism with DNA hypermethylation in the Zucker (type 2) diabetic fatty rat. Diabetes Metab Res Rev, 2012, 28: 123-131

54 Akçay T, Dinçer Y, Celebi N, Ilkova H. O(6)-methylguanine DNA methyltransferase activity in diabetic patients. Diabetes Res Clin Pract, 2003, 61: 1-6

55 Olsen AS, Sarras MP, Leontovich A, Intine RV. Heritable transmission of diabetic metabolic memory in zebrafish correlates with DNA hypomethylation and aberrant gene expression. Diabetes, 2012, 61: 485-491

56 Miao F, Chen Z, Zhang L, Wang J, Gao H, Wu X, Natarajan R. RNA-sequencing analysis of high glucose-treated monocytes reveals novel transcriptome signatures and associated epigenetic profiles. Physiol Genomics, 2013, 45: 287-299

57 Villeneuve LM, Reddy MA, Lanting LL, Wang M, Meng L, Natarajan R. Epigenetic histone H3 lysine 9 methylation in metabolic memory and inflammatory phenotype of vascular smooth muscle cells in diabetes. Proc Natl Acad Sci USA, 2008, 105: 9047-9052

58 Miao F, Chen Z, Genuth S, Paterson A, Zhang L, Wu X, Li SM, Cleary P, Riggs A, Harlan DM, Lorenzi G, Kolterman O, Sun W, Lachin JM, Natarajan R; DCCT/EDIC Research Group. Evaluating the role of epigenetic histone modifications in the metabolic memory of type 1 diabetes. Diabetes, 2014, 63: 1748-1762

59 Wang Q, Wang Y, Minto A, Wang J, Shi Q, Li X, Quigg RJ. MicroRNA-377 is up-regulated and can lead to increased fibronectin production in diabetic nephropathy. FASEB J, 2008, 22: 4126-4135

60 Zhang Z, Peng H, Chen J, Chen X, Han F, Xu X, He X, Yan N. MicroRNA-21 protects from mesangial cell proliferation induced by diabetic nephropathy in $\mathrm{db} / \mathrm{db}$ mice. FEBS Lett, 2009, 583: 2009-2014

61 Feng B, Chen S, McArthur K, Wu Y, Sen S, Ding Q, Feldman RD, Chakrabarti S. miR-146a-mediated extracellular matrix protein production in chronic diabetes complications. Diabetes, 2011, 60: 2975-2984

62 Syreeni A, El-Osta A, Forsblom C, Sandholm N, Parkkonen M, Tarnow L, Parving HH, McKnight AJ, Maxwell AP, Cooper ME, Groop PH; FinnDiane Study Group. Genetic examination of SETD7 and SUV39H1/H2 methyltransferases and the risk of diabetes complications in patients with type 1 diabetes. Diabetes, 2011, 60: 3073-3080

63 Maghbooli Z, Hossein-Nezhad A, Larijani B, Amini M, Keshtkar A. Global DNA methylation as a possible biomarker for diabetic retinopathy. Diabetes Metab Res Rev, 2015, 31: 183-189

64 Maghbooli Z, Larijani B, Emamgholipour S, Amini M, Keshtkar A, Pasalar P. Aberrant DNA methylation patterns in diabetic nephropathy. J Diabetes Metab Disord, 2014, 13: 69

65 Zhong Q, Kowluru RA. Role of histone acetylation in the development of diabetic retinopathy and the metabolic memory phenomenon. J Cell Biochem, 2010, 110: 1306-1313

66 Kadiyala CS, Zheng L, Du Y, Yohannes E, Kao HY, Miyagi M, Kern TS. Acetylation of retinal histones in diabetes increases inflammatory proteins: effects of minocycline and manipulation of histone acetyltransferase (HAT) and histone deacetylase (HDAC). J Biol Chem, 2012, 287: 25869-25880

67 Nishikawa T, Edelstein D, Du XL, Yamagishi S, Matsumura T, Kaneda Y, Yorek MA, Beebe D, Oates PJ, Hammes HP, Giardino I, Brownlee M. Normalizing mitochondrial superoxide production blocks three pathways of hyperglycaemic damage. Nature, 2000, 404: 787-790

68 Kowluru RA. Mitochondria damage in the pathogenesis of diabetic retinopathy and in the metabolic memory associated with its continued progression. Curr Med Chem, 2013, 20: 3226-3233

69 Kanwar M, Chan PS, Kern TS, Kowluru RA. Oxidative damage in the retinal mitochondria of diabetic mice: possible protection by superoxide dismutase. Invest Ophthalmol Vis Sci, 2007, 48: 3805-3811

70 Zhong Q, Kowluru RA. Epigenetic changes in mitochondrial superoxide dismutase in the retina and the development of diabetic retinopathy. Diabetes, 2011, 60: 1304-1313

71 Zhong Q, Kowluru RA. Epigenetic modification of Sod2 in the development of diabetic retinopathy and in the metabolic memory: role of histone methylation. Invest Ophthalmol Vis Sci, 2013, 54: 244-250

72 Zhong Q, Mishra M, Kowluru RA. Transcription factor Nrf2mediated antioxidant defense system in the development of diabetic retinopathy. Invest Ophthalmol Vis Sci, 2013, 54: 3941-3948

73 Mishra M, Zhong Q, Kowluru RA. Epigenetic modifications of Nrf2mediated glutamate-cysteine ligase: implications for the development of diabetic retinopathy and the metabolic memory phenomenon associated with its continued progression. Free Radic Biol Med, 2014, 75C: $129-139$

74 Mishra M, Zhong Q, Kowluru RA. Epigenetic modifications of Keap1 regulate its interaction with the protective factor Nrf2 in the development of diabetic retinopa. Invest Ophthalmol Vis Sci, 2014, 55: 7256-7265

75 Kowluru RA. Role of matrix metalloproteinase-9 in the development of diabetic retinopathy and its regulation by H-Ras. Invest Ophthalmol Vis Sci, 2010, 51: 4320-4326

76 Kowluru RA, Zhong Q, Santos JM. Matrix metalloproteinases in diabetic retinopathy: potential role of MMP-9. Expert Opin Investig Drugs, 2012, 21: 797-805

77 Kowluru RA, Santos JM, Zhong Q. Sirt1, a negative regulator of matrix metalloproteinase-9 in diabetic retinopathy. Invest Ophthalmol Vis Sci, 2014, 55: 5653-5660

78 Zhong Q, Kowluru RA. Regulation of matrix metalloproteinase-9 by epigenetic modifications and the development of diabetic retinopathy. Diabetes, 2013, 62: 2559-2568

79 Perrone L, Devi TS, Hosoya K, Terasaki T, Singh LP. Thioredoxin interacting protein (TXNIP) induces inflammation through chromatin modification in retinal capillary endothelial cells under diabetic 
conditions. J Cell Physiol, 2009, 221: 262-272

80 Perrone L, Matrone C, Singh LP. Epigenetic modifications and potential new treatment targets in diabetic retinopathy. J Ophthalmol, 2014, 2014: 789120

81 Thomson DW, Bracken CP, Goodall GJ. Experimental strategies for microRNA target identification. Nucleic Acids Res, 2011, 39: 6845-6853

82 Caroli A, Cardillo MT, Galea R, Biasucci LM. Potential therapeutic role of microRNAs in ischemic heart disease. J Cardiol, 2013, 61: 315-320

83 Silva VA, Polesskaya A, Sousa TA, Corrêa VM, André ND, Reis RI, Kettelhut IC, Harel-Bellan A, De Lucca FL. Expression and cellular localization of microRNA-29b and RAX, an activator of the RNAdependent protein kinase (PKR), in the retina of streptozotocininduced diabetic rats. Mol Vis, 2011, 17: 2228-2240

84 Mastropasqua R, Toto L, Cipollone F, Santovito D, Carpineto P, Mastropasqua L. Role of microRNAs in the modulation of diabetic retinopathy. Prog Retin Eye Res, 2014, 43C: 92-107

85 Choi KC, Jung MG, Lee YH, Yoon JC, Kwon SH, Kang HB, Kim MJ, Cha JH, Kim YJ, Jun WJ, Lee JM, Yoon HG. Epigallocatechin3-gallate, a histone acetyltransferase inhibitor, inhibits EBV-induced B lymphocyte transformation via suppression of RelA acetylation. Cancer Res, 2009, 69: 583-592

86 Wood JG, Rogina B, Lavu S, Howitz K, Helfand SL, Tatar M, Sinclair D. Sirtuin activators mimic caloric restriction and delay ageing in metazoans. Nature, 2004, 430: 686-689
87 Morimoto T, Sunagawa Y, Kawamura T, Takaya T, Wada H, Nagasawa A, Komeda M, Fujita M, Shimatsu A, Kita T, Hasegawa K. The dietary compound curcumin inhibits p300 histone acetyltransferase activity and prevents heart failure in rats. J Clin Invest, 2008, 118: 868-878

88 Majid S, Dar AA, Ahmad AE, Hirata H, Kawakami K, Shahryari V, Saini S, Tanaka Y, Dahiya AV, Khatri G, Dahiya R. BTG3 tumor suppressor gene promoter demethylation, histone modification and cell cycle arrest by genistein in renal cancer. Carcinogenesis, 2009, 30: 662-670

89 Bassett SA, Barnett MP. The role of dietary histone deacetylases (HDACs) inhibitors in health and disease. Nutrients, 2014, 6: 4273-4301

90 Marsh DJ, Shah JS, Cole AJ. Histones and their modifications in ovarian cancer-drivers of disease and therapeutic targets. Front Oncol, 2014, 4: 144

91 Itamochi $H$. Targeted therapies in epithelial ovarian cancer: molecular mechanisms of action. World J Biol Chem, 2010, 1: 209-220

92 Song SH, Han SW, Bang YJ. Epigenetic-based therapies in cancer: progress to date. Drugs, 2011, 71: 2391-2403

93 Kim J, Hwang J, Jeong H, Song HJ, Shin J, Hur G, Park YW, Lee SH, Kim J. Promoter methylation status of VEGF receptor genes: a possible epigenetic biomarker to anticipate the efficacy of intracellular-acting VEGF-targeted drugs in cancer cells. Epigenetics, 2012, 7: 191-200

Open Access This article is distributed under the terms of the Creative Commons Attribution License which permits any use, distribution, and reproduction in any medium, provided the original author(s) and source are credited. 